\title{
Working Hypotheses About the Possibilities of Valvular Gastroenterology
}

\author{
Martynov VL* \\ Headquarters of the State Educational Establishment of the City of Nizhny Novgorod, Russia \\ *Corresponding author: Martynov VL, Headquarters of the State, Educational Establishment of the City of Nizhny Novgorod, Russia
}

\section{Introduction}

Currently, there is a paradoxical situation where the dominant medical opinion recognizes the harmfulness of dysfunction of such barrier structures as cardia, gatekeeper, Oddi's sphincter, heart valves, lower extremity vein valves, etc., but ignores the failure of the ileocecal locking device (Bauhinia valve) as a possible cause of the pathology of the digestive system, as well as various extraintestinal diseases. According to our data, based on the analysis of 976 irrigoscopy, the failure of the bauhinia valve (NBZ) was detected in $56 \%$ of cases. Despite these facts, practical and scientific medicine does not pay attention to this phenomenon. In this article, I would like to refer to the NBZ clinic, some etiopathogenetic links in the development of various pathologies of the body from the standpoint of valvular gastroenterology, to acquaint with the scientific and practical results of surgical correction of the defect, to highlight the possible perspectives of the method, i.e. to put forward working hypotheses readers to invite them to joint scientific and practical cooperation. Over 15 years of studying this problem, 281 patients aged from 6 to 67 years old have been subjected to surgical treatment for NBZ. All operations were performed according to original methods after confirming the pathology with an irrigoscopy method. In 73 patients, the surgical benefit was supplemented with correction of the identified chronic violation of duodenal patency (CNDP). According to the apt expression YaD Vitebsk [1], the gastrointestinal tract (GIT) is a one-way road. Any oncoming traffic on such a road is the road to an accident. Such one-sidedness in the gastrointestinal tract is determined by a series of valves, which are divided into two groups: absolute and relative action. Valves absolute action normally always pass the contents of the overlying departments in the underlying. Movement of the contents in the opposite direction (this will be considered reflux) will necessarily cause pathology. There are two valves of absolute action: the sphincter of the Vater papilla and the ileocecal obturator (Bauhinia valve). Valves of relative action in some conditions may allow reflux from the lower parts to the overlying ones, which is an adaptive response. From the standpoint of valvular gastroenterology, we will try to present the etiopathogenesis, the principles of treatment and the first results of certain diseases from both the gastrointestinal tract and outside it.

We assign one of the leading roles in the digestive system to the ileocecal locking apparatus, which delimits the functions of the small and large intestines, isolating the small intestine from the reflux of the large intestinal contents, which differs sharply in chemical composition, physical condition and bacterial spectrum. As a result of the NBZ, billions of colon microbes are thrown into the small intestine, colonization of the small intestine with allochtonic (alien) microorganisms occurs, which leads to the development of putrefactive and fermentative processes in the small intestine. The waste products of microorganisms - indole, phenol, cresol, skatole, pyrocatechin, carbolic acid, hydrogen sulfide, mercaptan, ethane, methane, etc. - infect the mucous membrane of the small intestine and, being absorbed into the bloodstream, cause autointoxication phenomena. These metabolites cannot be sufficiently detoxified, especially in liver diseases. Toxic, invasive and often necrotic properties, microbes contribute to the destruction of the intestinal wall, as well as dystrophic, destructive and necrotic changes of the mucous membrane. In this case, the barrier role of the intestinal wall is violated. The intestine becomes the entrance gate of the infection, as evidenced by non-specific bacteremia in patients with intestinal dysbiosis and the formation of foci of endogenous infection. The lymphoid tissue in the course of the gastrointestinal tract also suffers as a result of the chronization of the process, and the result is a deficiency of immunoglobulins A and M. The organism becomes less protected before microbial aggression.

In addition to the toxic effect on the intestine, the waste products of bacteria have a similar effect on the liver, gallbladder, stomach, pancreas. As a result of inflammation of the wall of the 
small intestine, lymphatic vessels and lymph nodes located in the retroperitoneal space and around the duodenum, adhesions develop around the latter, as well as in the initial part of the jejunum. These parts of the intestine are located mesoperitoneally and do not have a mesentery, which limits their mobility and contributes to the adhesive process. Fibrous cords (due to adhesions) and enlarged lymph nodes squeeze the end section of the duodenum from the outside, which makes it difficult for the contents of the duodenum to exit, increasing the cavity pressure in it. Hypertension in the duodenum makes it difficult for secretions to escape from the organs that flow into it (from the gallbladder, pancreas, liver, stomach), which leads to chronic inflammation in these organs. Colonization by microbes can cause an infectious process in them.

Disruption of the general condition arises from the period of the disease when absorption in the small intestine begins to suffer. Therefore, in varying degrees, it occurs in most chronic enteritis. There are forms of chronic enteritis, which manifest exclusively general symptoms, seemingly unrelated to the intestinal tract, and only a thorough clinical examination reveals the true nature of the disease: a violation of the protein metabolism, the digestive systems of the digestive tract, fat metabolism, phospholipids, cholesterol, carbohydrate violation, vitamin, mineral metabolism, endocrine insufficiency, disorders of hematopoiesis, nervous system, pathology of the skin, lungs, cardiovascular system. For laboratory confirmation of chronic auto-intoxication, we determined such indicators as urine indican, the level of average serum molecules, lipid peroxidation, and lipid metabolism. It turned out that in case of the failure of the Bauhinia valve, the qualitative response of urine to indican is positive in $95 \%$ of cases (normally this reaction is negative), the level of medium molecules is increased in $77 \%$ of patients (on average this value exceeded the norm by $43.5 \%$ ) normal rates are in $8 \%$, b-lipoproteins - in 18\%, triglycerides - in $25 \%$, atherogenic coefficient - in $45 \%$, serum lipid peroxidation - in $52 \%$ of patients.

These indicators prove the presence of chronic autointoxication in NBZ and indirectly confirm the theory of aging. II Mechnikov [2-6] as a result of prolonged autointoxication coming from the colon 2, 3. As a result of Bauginoplasty, the reaction of urine to indican turned out to be positive only in $5 \%$ of observations, but even then, after a relapse of the NBZ due to the imperfection of the procedure used at first. Studies of 147 patients with NBZ allowed us to determine the clinical picture of the disease (Table1). Comparing the clinical manifestations before and after the surgical correction of the ileocecal locking apparatus, we can conclude that it was created by nature for good reason. Consider the clinical manifestations of NBZ and HNDP, the possibility of their correction in the etiopathogenesis and treatment of some nosological forms.

Table 1: Clinical picture with NBZ and studied nosological units (\%).

\begin{tabular}{|c|c|c|c|c|c|c|c|c|c|c|c|}
\hline \multirow{3}{*}{$\begin{array}{l}\text { Clinical } \\
\text { manifes } \\
\text { tations }\end{array}$} & \multirow{3}{*}{$\begin{array}{c}\text { Before } \\
\text { surgery } \\
\mathrm{N}=318\end{array}$} & \multicolumn{3}{|c|}{ NBZ (\%) } & \multirow{3}{*}{$\begin{array}{c}\text { Peptic } \\
\text { ulcer } \\
\text { and } \\
12-\text { pc } \\
\mathrm{N}=149\end{array}$} & \multirow{3}{*}{$\begin{array}{c}\text { Bronchial } \\
\text { asthma } \\
\mathrm{N}=228\end{array}$} & \multirow{3}{*}{$\begin{array}{l}\text { Dermatosis } \\
\qquad N=54\end{array}$} & \multirow{3}{*}{$\begin{array}{c}\text { Diabetes } \\
\mathrm{N}=100\end{array}$} & \multirow{3}{*}{$\begin{array}{c}\text { Rheumatoid } \\
\text { Diseases } \\
\mathrm{N}=49\end{array}$} & \multirow{3}{*}{$\begin{array}{c}\text { Gallstone } \\
\text { disease } \\
\mathrm{N}=126\end{array}$} & \multirow{3}{*}{$\begin{array}{c}\text { Colon } \\
\text { cancer } \\
\mathrm{N}=104\end{array}$} \\
\hline & & & ropera & & & & & & & & \\
\hline & & Yes & $\begin{array}{c}\text { Less } \\
\text { often } \\
\text { less }\end{array}$ & not & & & & & & & \\
\hline Stomach ache & 100 & 17 & 25 & 58 & 100 & 63 & 78 & 51 & 74 & 82 & 99 \\
\hline \multirow[t]{2}{*}{$\begin{array}{l}\text { Heaviness in } \\
\text { the stomach } \\
\text { after eating }\end{array}$} & 79 & 4 & & 83 & 69 & 61 & 51 & 35 & 38 & 62 & 33 \\
\hline & & & 13 & & & & & & & & \\
\hline Belching air & 80 & 8 & 22 & 70 & 73 & 61 & 53 & 42 & 38 & 63 & 34 \\
\hline Spit-up food & 52 & 2 & 4 & 94 & 32 & 45 & 12 & 24 & 14 & 38 & 10 \\
\hline $\begin{array}{l}\text { Epigastric } \\
\text { heartburn }\end{array}$ & 68 & 2 & 0 & 98 & 80 & 74 & 56 & 21 & 25 & 66 & 45 \\
\hline $\begin{array}{l}\text { Heartburn } \\
\text { behind the } \\
\text { sternum }\end{array}$ & 68 & 8 & 2 & 90 & 10 & 74 & 56 & 31 & 26 & 62 & 48 \\
\hline Bitter mouth & 73 & 4 & 2 & 93 & 18 & 74 & 15 & 0 & 47 & 60 & 43 \\
\hline Nausea & 79 & 4 & 8 & 88 & 73 & 49 & 34 & 26 & 37 & 38 & 20 \\
\hline Constipation & 73 & 6 & 10 & 84 & 56 & 47 & 56 & 45 & 40 & 51 & 50 \\
\hline Diarrhea & 51 & 4 & 6 & 90 & 21 & 43 & 49 & 20 & 20 & 26 & 38 \\
\hline Relaxing chair & 65 & 14 & 26 & 60 & 27 & 43 & 49 & 20 & 20 & 49 & 66 \\
\hline $\begin{array}{l}\text { Intolerance to } \\
\text { milk and other } \\
\text { foods }\end{array}$ & 55 & 13 & 4 & 83 & 17 & 41 & 44 & 25 & 25 & 48 & 23 \\
\hline Fatigue & 92 & 17 & 17 & 66 & 95 & 92 & 63 & 88 & 83 & 80 & 80 \\
\hline Weight loss & 54 & 20 & 0 & 80 & 46 & 43 & 19 & 56 & 28 & 50 & 75 \\
\hline
\end{tabular}




\begin{tabular}{|c|c|c|c|c|c|c|c|c|c|c|c|}
\hline $\begin{array}{l}\text { Unpleasant } \\
\text { smell from the } \\
\text { mouth }\end{array}$ & 75 & 8 & 14 & 78 & 77 & 52 & 17 & 50 & 37 & 64 & 29 \\
\hline Bloating & 79 & 10 & 10 & 80 & 80 & 62 & 41 & 38 & 45 & 54 & 36 \\
\hline $\begin{array}{l}\text { Rumbling in } \\
\text { the stomach }\end{array}$ & 95 & 14 & 39 & 47 & 80 & 62 & 71 & 64 & 74 & 75 & 54 \\
\hline Heartbeat & 65 & 14 & 6 & 80 & 27 & 77 & 68 & 68 & 62 & 66 & 56 \\
\hline Dizziness & 72 & 10 & 16 & 74 & 16 & 66 & 71 & 71 & 66 & 62 & 53 \\
\hline $\begin{array}{l}\text { Darkening } \\
\text { eyes }\end{array}$ & 66 & 8 & 16 & 76 & 14 & 70 & 58 & 58 & 63 & 53 & 43 \\
\hline
\end{tabular}

\section{Surgical Correction of Immunological Hyporeactivity}

The achievements of modern immunology contributed to the deepening of ideas about the causes and mechanisms of development of many human diseases. The immune system is the totality of all lymphoid organs and accumulations of human lymphoid cells. Antigens that carry a sign of genetic foreignness, when introduced into the body, cause the development of specific immunological reactions. Studies of the lymphoid tissue associated with the gastrointestinal tract have three main groups of immunological elements: lymphoid follicles located all over the intestinal tube, plasma and T-lymphoid cells diffusely infiltrating the mucous membrane of the digestive organs, small unidentified cells. It was found that in $82.4 \%$ of patients with chronic colitis, in $70 \%$ of patients with chronic enterocolitis, a marked decrease in the immunological reactivity of the organism in patients with gastrointestinal diseases is observed. There is a clear dependence of the degree of change of immunological resistance on the severity of the clinical picture of the disease, a decrease in protection factors reflects the inhibition of body reactivity, while an increase in the content of these factors in the blood indicates the intensity of immune processes and is an indicator of compensatory-adaptive reactions 4 . The more severe the chronic enterocolitis than the longer its duration, the lower the level of general reactivity of the organism, the lower the level of natural immunity. We set the task to study the general resistance of the organism in the NBZ and after plastic surgery for its correction, without going into details of each case of clinical observation. The work was done in collaboration with the Department of Microbiology of the Novosibirsk State Medical Academy. Blood sera were randomly taken from 20 patients with NBZ and from 22 patients after Bauginoplasty performed according to our method for 1-2 years after surgery. The content of antibodies to peptidoglycan Staphylococcus aureus (strain 885, solubilized by ultrasound) was determined. Each sample was placed in 3 repetitions, calculating the average result. Peptidoglycan is a structural component of the cell wall of all bacteria, which, in addition to its individual features, has a certain immunological community, which makes it possible to indirectly judge the content of anti-peptidoglycan antibodies as a whole. In the group of 20 patients with chronic enterocolitis and NBZ, the content of antibodies to peptidoglycan Staphylococcus aureus exceeded that in practically healthy people (positive control) in 8 patients (40\%), it was less in 12 (60\%). The antibody content is more than 2 times higher than in healthy patients in 3 patients (15\%). In the group of 22 patients who were performed Bauginoplasty 1-2 years ago, the content of antibodies to peptidoglycan was higher than in practically healthy people (positive control), in 14 (64\%), less - in 8 (36\%). The antibody content is more than 2 times higher than in healthy patients in 9 patients (41\%). These figures indicate a stronger immunity in the well-off Bauhinia valve.

\section{Lipid Exchange}

Synthesis of cholesterol (cholesterol) occurs in cells of almost all organs and tissues, but in significant amounts in the liver $(80 \%)$, the wall of the small intestine $(10 \%)$ and the skin (5\%). It is in the liver and the wall of the small intestine that lipoproteins containing cholesterol are formed. Cholesterol catabolism occurs in the liver (cholesterol oxidation to bile acids), in the adrenal glands and placenta (formation of corticoid hormones from cholesterol), follicular tissue and ovaries (formation of steroid sex hormones). The role of high density lipoproteins (HDL) in the body is primarily determined by their participation in cholesterol homeostasis in the blood plasma and tissues due to the involvement in the so-called reverse transport of cholesterol. HDL cholesterol is transported from the tissues to the liver for oxidation to bile acids, which increases their anti-atherogenic activity. The formation of HDL occurs mainly in two ways: 1) in hepatocytes and enterocytes; 2) in the blood stream. The catabolism of HDL occurs mainly in the kidneys, liver, ovaries, adrenal glands. Low density lipoproteins (LDL) are formed mainly in the blood and to a lesser extent - in the liver. But the role of the liver in the direct synthesis of LDL is especially increasing in severe forms of type II hyperlipoproteinemia. LDL catabolism occurs mainly in the liver (50-60\%). The remainder is in the peripheral tissue cells. LDL transports cholesterol to the cell, which is their atherogenic effect. It is believed that the development of atherosclerosis depends not so much on the level of total cholesterol in the blood plasma, but on its distribution between different classes of lipoproteins (LP) or, in other words, on the ratio of LDL and HDL. Normally, there is a 30 -fold molar predominance of anti-atherogenic drugs (HDL) over atherogenic (LDL) in human blood, and the weakening of such predominance may be the cause of atherosclerosis. Currently proposed surgical methods for the correction of hypercholesterolemia, not amenable to dietoperia and drug effects. 
Thus, a partial ileoshuntirovanii operation, known as the Buchwald operation, is used, but it has a lot of side effects. Of the other methods of surgical correction of hypercholesterolemia, liver transplants should be mentioned. However, so far in the world only a few such operations have been performed by patients with familial homozygous hypercholesterolemia. The pronounced hypocholesterolemic effect of liver transplantation is an excellent example illustrating the importance of the role of the liver in LDL and cholesterol homeostasis 5. When NBZ and HNDP for various reasons suffers and the liver. We present data on lipid metabolism in patients who have been diagnosed with NBZ 6 according to irrigoscopy, and our data in patients who have previously undergone Bauginoplasty (Table 2). Thus, a working hypothesis is proposed on a new method of surgical correction of lipid metabolism disorders. Considering the effect of the gastrointestinal tract on the etiopathogenesis of diseases such as bronchial asthma (BA), various pharmacomycoses, rheumatoid diseases, diabetes mellitus, cholelithiasis, gastric ulcer (GAB) and duodenal ulcers, colon cancer, we have determined the NBD clinic in patients with the specified pathological forms and without them (Table 1). Consider the results obtained.

Table 2: Lipid metabolism status in patients with NBC and after biogenetic, \%.

\begin{tabular}{|c|c|c|}
\hline & When NBZ (data by V. p. Troshina) N=193 & After biogenetic (our record) $\mathrm{N}=54$ \\
\hline Indicators & \multicolumn{2}{|c|}{ LIPID METABOLISM } \\
\hline Normolipidemia $\mathrm{N}=193$ & 20 & 84 \\
\hline Hyperlipidemia $\mathrm{N}=193$ & 72 & 16 \\
\hline Hypolipidemia N=193 & 8 & 0 \\
\hline Age & \multicolumn{2}{|c|}{ HYPERLIPIDEMIA } \\
\hline $20-29$ years & 60 & 16 \\
\hline $30-39$ years & 74 & 38 \\
\hline $40-49$ years & 85 & 30 \\
\hline
\end{tabular}

\section{Contact with Food Allergies}

Allergic manifestations outside the digestive system were observed in $21 \%$ of patients with food allergies, which was present in $21.7 \%$ of patients with asthma, and in $4.1 \%$ of cases it was the main and only cause of asthma 7. The digestive tract is not only an organ through which various allergens can enter the body through absorption, but also a place where allergic reactions occur. In such cases, it acts as a shock organ in which the antigen - antibody reaction develops. According to our data, dystophic, atrophic, inflammatory changes develop in the digestive system in the NBZ and often associated with CNP, which contributes to the violation of splitting and increase the likelihood of penetration into the body not only food, but also their impurities, preservatives, medicines and toxins of bacteria, fungi, parasites and other protein-containing substances. In gastroenteritis, in adults, the absorption of allergens increases 4 times, and in children - 5-6 times or more (it should be recalled that the formation of the Bauhinia valve ends by 5-6 years old) 7. As a result, NBZ does not have a liver due to endo toxicosis. sufficiently prevents the entry of allergens from the digestive tract into the general circulation, which causes secondary sensitization of the body. 81 people (55\% of patients) noted the intolerance of various foods. The overwhelming majority of patients with asthma and dermatosis clearly indicated food products, after consumption of which bronchospasm or skin changes occur. In addition, they noted the increased manifestations of gastro enterocolitis (nausea, vomiting, rumbling and bloating, abdominal pain, weakened stools, diarrhea, as well as weakness, sweating, palpitations). With FGDS in all patients signs of gastro duodenitis; gastric probing revealed normal acidity - in 14\% of cases, hyperacidity - in 30\%, hypoacidity
- in 21\%, anacidism - in 35\%; Ultrasound revealed signs of cholecystitis in $71 \%$ and pancreatitis in $22 \%$ of cases; duodenal sounding - signs of cholecysto cholangitis in $100 \%$ of cases; her fluoroscopy with a probe without hypotension is a sign of CKDP in almost all patients; fibro colonoscopy - ileitis in 58\%, colitis - in $86 \%$ of cases; dysbacteriosis of the colon was detected in $62 \%$ of cases; $95 \%$ - small intestinal dysbiosis by reaction of urine to indican; the level of medium molecules is increased in $77 \%$ of patients (on average by $43.5 \%$ of the norm), almost all of them have a coprogram violation. These data suggest that the NBZ and HNDP create all the conditions for the development of various etiopathogenesis links of food allergies. All patients underwent Bauginoplasty, and in 73 cases, a correction of CNP in the form of a Treitz ligament incision or duodenojejunostomy. In terms of up to 1 year after surgery, it became possible to consume foods that previously caused allergic reactions, without prejudice to health. In all patients with asthma, any food products do not cause suffocation, and patients with dermatitis do not have any progress.

\section{Relationship with Vegetative Dystonia Syndrome}

The syndrome of vegetative dystonia (SVD) is caused by a complex of pathogenic factors. Manifestations of this syndrome are diverse and include, in addition to general clinical disorders, valvular dysfunction. In particular, myocardial valve dysfunction is distinguished. A comprehensive survey of 120 patients with NBZ using tests for endogenous intoxication (qualitative reaction of urine to indican, the level of medium molecules in serum), malabsorption syndrome, routine GI examination methods, tabular methods for determining autonomic tone, interval cardiography with complex treatment were carried out. SVD was detected in 
$32 \%$ of patients and is manifested by increased fatigue, dizziness, palpitations, headaches, hyperhidrosis, vasomotor lability. The vegetative tone of the majority of patients changed in the direction of sympathicotonia: in $57 \%$ there was a moderate increase in sympathetic tone, in $20 \%$ - pronounced. Only in $2 \%$ of patients, the predominance of the parasympathetic tone of the autonomic nervous system was revealed. All patients underwent followup treatment for gastro enterocolitis for 5-15 years without significant improvement. In this regard, he underwent an operation to correct the ileocecal locking apparatus. In $88 \%$ of patients, a significant improvement occurred in the form of the disappearance or reduction of gastro enterocolitis and the disappearance of SVD in $66 \%$. In $17 \%$ of cases there was a decrease in SVD.

\section{Relationship with Asthma}

According to the literature, the etiopathogenetic relationship between the gastrointestinal tract and BA is noted in $40-82 \%$.

In this case, the following relationships are distinguished:

a) Duodeno gastroesophageal reflux followed by microaspiration of hydrochloric acid molecules and bile salts;

b) Re-stimulation of the vagus nerve with the emergence of numerous afferent impulses in the central nervous system with subsequent pathological efferent impulses in the bronchopulmonary system;

c) Hyperacid state of the stomach;

d) Hernia of the esophageal opening of the diaphragm;

e) Chronic auto-intoxication emanating from the digestive system;

f) Food allergies;

g) Impaired immune function of the gastrointestinal tract;

h) Dysbacteriosis.

We interviewed 169 patients with asthma. The overwhelming majority of patients had clinical manifestations of pathology, which, according to our data, corresponds to the NBZ (Table 1) and CNDP. 40 patients with BA were operated on the background of NBZ and HNDP. He underwent surgical correction of NBZ and HNDP. The results obtained can be divided into three groups:

I. Some patients in the immediate and late postoperative period do not note attacks of suffocation and do not take drugs. The dissection of the Treitz ligament was adequate in the correction of HNDP, since the distance between the aorta and the superior mesenteric artery (VMA) at the level of the lower horizontal part of the duodenum was in these patients more than $10 \mathrm{~mm}$.

II. Some patients continue to note the principles of suffocation, but they have become much less common and do not require constant medication. It is noted that the more time has passed since the operation, the better their condition and state of health become. This group has not been adequately corrected for HNDP in the form of duodenojejunostomy. They have a distance of $10 \mathrm{~mm}$ or less between the aorta and the VMA at the level of the lower horizontal part of the duodenum. The dissection of the Treitz ligament was ineffective.

III. One patient does not notice improvement. He revealed a clear dependence of attacks of breathlessness on the emotional state.

IV. Thus, it is possible to put forward a working hypothesis that the identification and adequate surgical correction of NBZ and CNP can be etiopathogenetic links in the treatment of some forms of asthma.

\section{Contact with Dermatosis}

The following etiopathogenetic links in the development of dermatoses are distinguished.

I. Changes in acid-base balance in the lumen of the small intestine, food ingress becomes an antigen for it. Immune complexes are formed in the intestines, including auto-tissues, which penetrate the blood and settle in various tissues, including the skin, where immediate and delayed types of hypersensitivity develop. Therefore, it seems most likely that the intestine, especially the small intestine, is the organ of the digestive tract most responsible for the development of dermatosis.

II. As a result of a violation of absorption in the small intestine, there is a shortage of many substances, in particular vitamins, whose participation in the pathogenesis of dermatosis is large.

III. Endointoxication in patients with dermatoses is manifested by a higher content of medium molecules (2-3 times compared with the norm) and therefore the use of sorbents, hemosorption, plasma exchange significantly improves the effect of therapy.

Complaints of 50 patients suffering from various forms of dermatosis were studied: psoriasis - $61 \%$, neurodermatitis - $27 \%$, rosacea $-7 \%$, systemic lupus erythematosus $-7 \%$, allergic reaction by type of Quincke's edema - $2.5 \%$. Of these, only $2.5 \%$ of patients showed no complaints of the gastrointestinal tract, the rest noted various gastroenterocolitic disorders (Table 1). Previously, they identified: chronic gastritis - in $62.5 \%$, chronic cholecystitis - in $37 \%$, chronic gastroduodenitis - in $12.5 \%$, chronic colitis - in $12.5 \%$, chronic pancreatitis - in $6 \%$, duodenal ulcer - $6 \%$. In $6 \%$ of patients, appendectomy for chronic appendicitis was previously performed. Irrigoscopy was performed in 32 patients with dermatoses, and all of them revealed a reflux of a contrast agent in the ileum (NBZ). He made a surgical correction of this pathology - bauginoplasty with the use of the dura mater; in some cases, the operation 
was supplemented with dissection of the ligament of Treutz to reduce the effects of CNDP. In the immediate postoperative period, there was a positive trend in the form of regression of skin manifestations and, accordingly, related complaints, namely: reduction or disappearance of itching, reduction of the area of eruptions and degree of severity, reduction of peeling and in some cases the complete disappearance of pathological elements on the skin regarded as the onset of remission. 3-12 months after surgery, the patients underwent an outpatient follow-up examination. In all, the condition is defined as stable remission during dermatosis. Also noted a decrease or disappearance of complaints of the gastrointestinal tract presented before the operation. In the process of monitoring changes in the dura mater placed on the serosa of the intestine, it was found that after 1-1.5 years, this strip becomes thinner to the diameter of a normal filament, fragmented and loses its function embedded in it when correcting the ileocecal locking apparatus. Therefore, unfortunately, after a specified time, the NBZ relapses with its clinical manifestations. The use of a strip of a vascular prosthesis for the correction of the NBZ (which was performed in two patients with dermatosis) ensures the reliability of the obturator function of the ileocecal junction. Professor NS Torgushina [7-10] carried out studies of skin biopsy specimens taken during surgery in patients with dermatoses with NBZ and in patients with NBZ without dermatoses 10. The detected changes were reduced to three morphological patterns similar in these two groups of patients. First, obligatory for all obtained skin preparations were dystrophic processes, expressed in the development of horny dystrophy of the epithelial layer, which was manifested by para- and hyperkeratosis; in the mucoid swelling of the fibrous structures of the papillary and reticular layers of the dermis, especially expressed under the basement membrane; in a permanent find in the skin of patients with NBZ hyalinosis, also particularly pronounced in the reticular layer; in the tendency to atrophy of the skin appendages (sweat and sebaceous glands), which was noted parallel to the development of connective tissue hyalinosis. The second group of morphological processes in the skin is the proliferation of cells, primarily capillary endothelial cells. The endothelium of most capillaries becomes high, juicy, often formed multi-row layers, almost completely overlapping the lumen of the vessel. It is interesting to note that the reaction is not associated with inflammation and, in our opinion, can be regarded as a manifestation of changes in the overall blood composition. To a lesser extent, proliferative changes related to cells of the epithelium, which occurred in the form of acanthosis foci. The third group of processes recorded in the skin was expressed as diffuse or focal dermatitis. The inflammatory process was productive in nature with a prevalence of lymphocytes in the cellular composition with moderate admixture of segmented leukocytes. Inflammations, as a rule, were combined with an intensive reaction of the vascular bed, edema, and extravasation. The severity of inflammatory is manifested.

\section{Communication with Rheumatoid Diseases}

In rheumatology, a separate type of arthritis occurs, occurring as a complication of intestinal disease, called enterogenous arthritis. The mechanism of the relationship is not yet clear, but arthritis never precedes bowel damage. It deepens in parallel with intestinal pathology. Still allocate reactive arthritis. In this case, the infection is located outside the joint cavity. This term is used to refer to arthritis that has developed after an intestinal or urinary infection. It is believed that the pathogenesis of such arthritis is mediated by immune complexes. With the absorption of bacterial agents, the production of antibodies to them occurs. The resulting immune complexes and settle in the joints with the development of arthritis. One clinical observation in the Design Bureau. Semashko's treatment of Reiter's syndrome after bauginoplasty and the elimination of CNDP with ineffective conservative treatment led to the assumption of the important role of the NBZ and CKDP in the etiopathogenesis of rheumatoid diseases. Complaints typical of NBZ and HNDP in 49 patients with rheumatoid diseases were investigated. Of these, 18 were diagnosed with rheumatoid arthritis, 17 had reactive arthritis, 5 had rheumatism, 5 had systemic lupus erythematosus, 2 had ankylosing spondylitis Bechterew, 1 had a disease of type 1 collagen deficiency, 1 had systemic scleroderma of chronic currents with damage to the joints, esophagus, skin, blood vessels. The vast majority of patients noted pathological manifestations of the gastrointestinal tract (Table 1). Thus, a working hypothesis is being advanced that the detection and surgical correction of NBZ and HNDP may be etiopathogenetic links in the treatment of rheumatoid diseases.

\section{Communication with Diabetes}

There are three points of view about the relationship of disorders in the gastrointestinal tract and diabetes mellitus (DM):

a. Diabetes is the primary disease, and disorders in the gastrointestinal tract - complications, i.e. secondary disorders;

b. disorders of the gastrointestinal tract are formed due to the treatment of diabetes;

c. violations in the gastrointestinal tract may be primary, and diabetes - secondary.

The result of the study of this relationship was the introduction of the concept of "enteroinsular axis." By the entero-axial axis, direct insulation of the islet cells by absorbed nutrients and signaling by endocrine factors and nerve structures is implied. The main candidate for the role of incretin is a gastroinhibitory polypeptide (HIP), the release of which depends on the absorption of nutrients. Therefore, a violation of the secretion of HIP is found in many gastrointestinal and metabolic diseases. In 1906, Moore, Edie and Abram assumed that the duodenum is produced by a chemical pathogen of internal secretion of the pancreas. La Barre noted that a humoral factor is produced in the intestines, which releases insulin 
or potentiates its release in response to glucose (it is called incretin) 12. Since 1967, the connection between the intestine and islets has been called the entero-insular axis. This axis is quite complex and involves direct stimulation of the islet cells by the substrate absorbed nutrients, as well as signaling from the intestine to the islands through endocrine factors and nerves. The ISU is most likely to claim the role of incretin. The release of this hormone depends on the absorption of nutrients, since their mere presence in the intestine does not induce the secretion of HIP. Thus, the release of HIP is stimulated by the absorption of monosaccharides 6 and fats 14. Moreover, the glucose-induced release of HIP depends mainly on the function of the duodenum, and the fat-induced release from the function of the jejunum, which is apparently due to the existence of two types of HIP containing cells with different sensitivity to glucose and fat. Physiologically, a decrease in the secretion of HIP and, consequently, insulin is attributed to inadequate nutrition (malabsorption), and slower absorption. These conditions develop with HNDP and NBZ. Considering the strong functional load on NBZ and CNP on the liver, where up to $30 \%$ of insulin normally collapses, it is very important to study the liver function, sugar curve before and after the surgical correction of the indicated pathology. Insulin is a protein, and the waste products of microflora, their enzymes, contain a significant amount of proteases. There is a high probability at the NBZ interaction in the liver of insulin produced in the pancreas and microbial waste products absorbed from the small intestine.

Naturally, there is an assumption of partial destruction of insulin in such a situation. Together with Dr. B.N. Sidnev (Department of Radioisotope Diagnostics, OCDDC), we performed the following experiment on the DLS device (USA). From one patient after breakfast and the introduction of $60.0 \mathrm{~mm} 40 \%$ glucose intravenously, after 60 minutes, pure serum was taken in 2 tubes for insulin determination. In the first test tube, the amount of insulin was $47.8 \mu \mathrm{IE} / \mathrm{ml}$, in the second test tube - $47.2 \mu \mathrm{IE} / \mathrm{ml}$

Table 3: The amount of insulin in the serum after different periods of incubation.

\begin{tabular}{|c|c|c|c|c|}
\hline \multirow{3}{*}{ Dilution $90 \mathrm{mkl}$ serum } & \multicolumn{4}{|c|}{ Incubation at temperature $37^{\circ}$} \\
\hline & \multicolumn{2}{|c|}{ Within 2 hours } & \multicolumn{2}{|c|}{ Within 6 hours } \\
\hline & $\begin{array}{l}\text { Insulin concentra- } \\
\text { tion } \mu \mathrm{IE} / \mathrm{ml}\end{array}$ & $\begin{array}{c}\text { Ruined insulin } \\
\mu \mathrm{IE} / \mathrm{ml}\end{array}$ & $\begin{array}{c}\text { Insulin } \\
\text { concentration } \mu \mathrm{IE} \\
/ \mathrm{ml}\end{array}$ & $\begin{array}{c}\text { Ruined insulin } \\
\mu \mathrm{IE} / \mathrm{ml}\end{array}$ \\
\hline$+10 \mathrm{ml} \mathrm{H}_{2} \mathrm{O}$ & 150,5 & & 136,1 & \\
\hline$+10 \mathrm{ml}$ of fecal extract dilution $10^{-9}$ & 128,2 & $-22,3$ & 124,9 & $-11,2$ \\
\hline$+10 \mathrm{ml}$ of fecal extract dilution $10^{-8}$ & 170,8 & $+20,3$ & 119,9 & $-6,2$ \\
\hline$+10 \mathrm{ml}$ of fecal extract dilution $10^{-7}$ & 124,5 & -26 & 138,2 & $+2,1$ \\
\hline$+10 \mathrm{ml}$ of fecal extract dilution $10^{-6}$ & 128,6 & $-22,1$ & 119,0 & $-7,1$ \\
\hline$+10 \mathrm{ml}$ of fecal extract dilution $10^{-5}$ & 137,7 & $-12,8$ & 98,2 & $-37,9$ \\
\hline$+10 \mathrm{ml}$ of fecal extract dilution $10^{-4}$ & 118,5 & -32 & 112,6 & $-23,5$ \\
\hline$+10 \mathrm{ml}$ of fecal extract dilution $10^{-3}$ & 107,5 & -43 & 129,0 & $-7,1$ \\
\hline$+10 \mathrm{ml}$ of fecal extract dilution $10^{-2}$ & 137,7 & $-12,8$ & 134,0 & $-2,1$ \\
\hline$+10 \mathrm{ml}$ of fecal extract dilution $10^{-1}$ & 149,5 & -1 & 165,3 & $+29,2$ \\
\hline$+10 \mathrm{ml}$ of fecal extract undiluted & 139,8 & $-10,7$ & 149,5 & $+13,4$ \\
\hline
\end{tabular}

Citation: Martynov VL. Working Hypotheses About the Possibilities of Valvular Gastroenterology. Curr Tr Gatsr \& Hepatol 2(2)- 2019. CTGH. MS.ID.000133. DOI: 10.32474/CTGH.2019.02.000133.

(this insulin is associated with iodine and antibodies, for which the calculation is made). Two series of 10 -fold dilutions with distilled water of extracts from the patient's feces $(50 \mathrm{~g}$ of feces $+450 \mathrm{ml}$ of saline) were also performed. Equal amounts of serum with insulin determined in it are added to each dilution of the extract. In the first series, the incubation of the resulting mixture at $37^{\circ} \mathrm{C}$ was $2 \mathrm{~h}$, in the second series - $6 \mathrm{~h}$. Both series of mixtures were then transferred to cold incubation for $17 \mathrm{~h}$. After that, insulin was determined at each dilution of both series. The difference between the amount of insulin in the serum without incubation and without the addition of fecal extract and the amount of insulin in each dilution after incubation with the addition of an extract from feces in both series determined the amount of insulin remaining destroyed (Table 3). Serum with the addition of distilled water with incubation at $37^{\circ} \mathrm{C}$ for $2 \mathrm{~h}$ (first control) and $6 \mathrm{~h}$ (second control) served as control for the determination of insulin. The amount of insulin in fasting blood serum is normally 2-20 $\mu \mathrm{IE} / \mathrm{ml}$, after eating - 20-60 $\mu \mathrm{IE} / \mathrm{ml}$. The data obtained show that the faecal extract can destroy insulin. In 4 cases, the amount of insulin increased, which is apparently due to failures in the experiment. We studied 100 patients with diabetes (Table 1). The impetus for this was the fact of normalization of the sugar profile in one patient who suffered from type II diabetes, asthma and chronic calculous cholecystitis, after cholecystectomy with the correction of CNDP in the form of a dissection of the ligament of Treitz and correction of the NBZ. Also passed and asthma attacks. Type II diabetes is characterized by normal insulin production in the pancreas, but lack of body tissue response or excessive destruction of insulin in the liver. Normally, up to $30 \%$ of insulin is destroyed in the liver. We concluded, confirming the opinions of other authors, that diabetes in a large proportion of cases is accompanied by the clinic of chronic gastroenterocolitis, which, according to our data, corresponds to such organic pathology as the NBZ and KNDP. Thus, a working hypothesis is being advanced that the elimination of NBZ and HNDP in some patients with diabetes can lead to regression of the latter.

Incubation at temperature $37^{\circ}$ 


\section{Link to Gallstone Disease}

Currently, there are three main reasons for the etiopathogenesis of cholelithiasis (JCB):

a. Metabolic disorders;

b. Inflammatory changes in the gallbladder wall;

c. Stagnation of bile.

I. Accordingly, the following data was studied for NBZ.

II. The growth of microflora from the "B" portion when probing the duodenum was obtained in $76 \%$ of cases, after bauginoplasty - only in $42 \%$. Thus, Bauginoplasty reduces the presence of microflora in the gallbladder. It should be noted that this operation reduces the presence of microflora in the gastric contents, and also significantly reduces the dysbiosis of the small intestine, which was determined by the qualitative response of urine to indican. These numbers explain the reason for the generally recognized ascending route of infection. The reason - NBZ.

III. The overwhelming majority of patients with NBZ (more than 95\%) have a CHNDP clinic, namely: belching with air, regurgitation of food, heartburn, bitter taste in the mouth. HNDP is the cause of difficulty in emptying the gallbladder, which leads to stagnation of bile.

IV. Phenomena of chronic cholecystocholangitis with chronic bronchitis in NBZ, according to the sensing of the duodenum and ultrasound, were detected in $100 \%$ of cases.

To clarify the possible association of NBZ and HNDP with JCB, clinical manifestations of the gastrointestinal tract pathology were studied in 126 patients suffering from chronic calculous cholecystitis (Table 1). All patients with JCB noted any complaints of the gastrointestinal tract. Of these, 106 performed an irrigoscopy, in which 35 patients (33\%) detected a reflux of a contrast agent into the ileum, i.e. NBZ was detected. The indirect sign of duodenogastric reflux (he himself is a sign of HNDP), namely, atrophy of the mucous membrane of the antrum, is determined in $64 \%$ of cases.

Thus, the following working hypothesis is put forward:

a. NBZ and HNDP are the basis of chronic non-calculous cholecystitis, JCB;

b. Early correction of NBZ and HNDP are JCB prophylaxis;

c. Undiagnosed NBZ and HNDP may underlie some forms of postcholecystectomy syndrome.

\section{Communication with Peptic Ulcer}

Peptic ulcer disease (PUD) occurs on the background of a violation of the neurohumoral regulation of the functions of the stomach and duodenum due to the aggressive effect of the acidpeptic component of the gastric juice on the mucous membrane with weakened protective properties. The main aggressive factor in duodenal ulcers are hydrochloric acid and pepsin, and in stomach ulcers - their combined action with bile acids, lysolecithin, pancreatic juice, which enters the stomach due to duodenogastric reflux (DGR). The protective barrier of the mucous membrane form:

a. A layer of thick mucus covering the epithelium of the stomach, and the bicarbonate ions contained in it (mucousbicarbonate barrier);

b. Apical cell membrane;

c. Basement membrane of cells 15 .

From the proposed positions, the GDR arises from HNDP. We in NBZ with hypertension in the small intestine on the basis of the processes of decay and fermentation in 35\% of cases revealed non-duodenal reflux. We consider this fact, and its reason - in the NBZ, as a very important, but nevertheless not diagnosed one of the causes of CNDP. It is the increasing non-duodenal reflux after isolated duodenojejunostomy that many authors doubt the correctness of the decisions made. After Bauhinoplasty, Junoduodenal reflux is revealed by us only after its inadequacy for various reasons. It is these facts that suggest the need for more frequent simultaneous performance of duodenojejunostomy and bauginoplasty in the surgical treatment of patients with gastric and duodenal ulcer [11-13]. It is very important to note the indications for duodenojejunostomy - the distance between the aorta and the superior mesenteric artery at the level of the lower horizontal part of the duodenum is less than $15 \mathrm{~mm}$. Such an approach largely eliminates GDR, which is recognized as the most important link in the etiopathogenesis of ulcer from the standpoint of valvular gastroenterology. The role of the GDR is proved by experimental data. So, NN Lawson [14-16], was designed by the model of constant GDR. After 6 months, a macro- and then microscopic picture of hypertrophic gastritis was detected. In this regard, cholecystogastrostomy by NA Bogoraz and gastroenterostomy did not justify the hopes of surgeons to achieve healing of ulcers, since in half of the cases even more severe pathology arose - peptic ulcers. RM Kirk [17] after stitching the bile duct into the stomach of rats also found the formation of ulcers in 13 animals from 30 operated. The work of NN Lawson [18] on the reversibility of mucosal changes.

To create a reflux gastritis, 6 dogs were resected by Reichel-Polia method. In all animals, gastritis was proven morphologically. When re-operation to eliminate DGR at $60 \mathrm{~cm}$ below the gastrointestinal anastomosis, interintestinal anastomosis was imposed according to the Roux method (with complete intersection and suturing of the afferent loop). In all dogs after the second operation, the previously induced gastritis was eliminated. In a significant number of cases, ulcer starts in childhood. It should be noted that the formation of the Bauhinia valve ends by 5-6 years of life, causing up to this age a functional NBZ. It is at this age that inflammatory changes 
often occur in the small and large intestine, which can easily lead to high mesenteric lymphadenitis and periduodenitis, which disturb the duodenal motor evacuation function. Familial predisposition to ulcer, and it is observed in about $25 \%$ of patients, can be explained by congenital abnormalities leading to CNP, in the form of arteriomesenteric compression, high fixation of duodenojejunal junction, etc. (barometric pressure), finds its explanation in the baroreceptor regulation (Vater-Pachini body) of the function of the ligament of Treitz and her muscles and the muscle fibers of the twelve, strengthened in this place duodenum. But this is not typical for areas with an even climate throughout the year, which was noted at the 1st congress of gastroenterologists. Duodenal ulcer most often precedes gastric ulcer, which is associated with a moderate degree of reflux, which is not always easy to identify, with the most initial forms of CNDP. In gastric ulcer, the degree of impairment is significant, GHD is massive, persistent, it is easily detected in all patients. 19. It is the GDR in the initial stages of the ulcer that irritates the G-cells of the antrum with hyperproduction of gastrin and pepsin, which is characteristic of duodenal ulcer guts. As the process is chronized, GHR is chronized, atrophy of the gastric mucosa occurs, and it is enterolized, which causes a decrease in secretion. This is characteristic of gastric ulcer.

Lengthening the time of evacuation of gastric contents in patients with PUD, despite its accelerated onset, is also associated with CNDP. Reverse intake of food masses mixed with alkaline juices of the duodenum and is a powerful stimulator of gastric secretion. The slowdown of the evacuation time served as the basis for creating a theory of antral stasis as a cause of ulceration 20. Increasing the acidity of the gastric juice in patients with ulcers healed under conservative treatment and an increase in the number of parietal cells in the stomach, suggesting restoration of the normal structure of the mucous membrane, strongly suggests reliability of the reflux theory of the pathogenesis of ulcer and high plasticity of regenerative processes in the mucous membrane. Quite frequent ineffectiveness of conservative treatment of YAB, especially with gastric localization, is associated with the presence of unresolved CNPD and GHD. The presence of nocturnal starvation secretion in patients with duodenal ulcer can be explained by DGR, which is facilitated by the horizontal position of the body during sleep, when other stimuli are absent. Such an understanding of the pathogenesis of ulcer does not contradict the existing theories of ulcer formation, but only gives them a certain place. Clinical manifestations of NBZ and HNDP in 106 patients suffering from ulcerative disease (Table 1 ), suggest that the vast majority of patients in this group have a gastrointestinal valve system pathology. After the Bauhinoplasty operation, the normidal state was detected in $35 \%$ of patients (before the operation it was in 12.5\%), hypoacidic in 9\% (before the operation -- 20\%), anacid-in 18\% (before the operation - in $33 \%$ ). The number of patients with hyperacid state increased by $2 \%$. DGR is registered in the same patients in whom it occurred before the operation [19]. According to EGD, DGR after surgery was found in 26\%, whereas before the operation - in $44 \%$ of cases. The elimination of hypertension in the small intestine on the basis of the processes of decay and fermentation in NBZ, as one of the factors of CNDP, in our opinion, has significantly improved the secretory function of the stomach in the form of its enhancement. The hyperacid state is due to the remaining generally recognized causes of HNDP. These data indirectly confirm the prospects for valvular gastroenterology in the treatment of ulcer. The existing isolated cases (9) of achieving stable remission in the course of ulcer after Bauginoplasty and adequate correction of CNDP do not allow us to draw more specific conclusions. We present only the interesting idea of Professor LI Kazimirova [20,21]: "It even seems justified to us that the risk of abandoning the ulcer is found when detecting obvious causes of duodenal obstruction and only performing operations such as duodenojejunostomy, especially in young people with a short ulcer history."

These pre-operative determination of the distance between the aorta and the superior mesenteric artery at the level of the lower horizontal part of the duodenum by CT and ultrasound, fluoroscopy duodenum probe without hypotension, floor manometry by open catheters, intraoperative diagnosis allows us to state that arteriomesenteric compression (namely, this reason KNDP is the most difficult in the diagnostic plan) is overwhelmingly diagnosed only with CT and ultrasound and very rarely during surgery. Eractions It is the lack of alertness, the possibility of diagnosing arteriomesenteric compression that often drives the doctor and patient into the incurable "functional" form of CNDP. The same applies to another reason for the CND - NBZ, which practical medicine does not pay attention. Based on clinical manifestations in the long term after surgery, we concluded that duodenojejunostomy is indicated when the distance between the aorta and the superior mesenteric artery at the level of the lower horizontal part of the duodenum is less than $15 \mathrm{~mm}$ and should be limited to dissection of the Treitz ligament. Bauginoplasty should always be performed for diseases of the gastrointestinal tract, as well as for the possible influence of the gastrointestinal tract on extraintestinal pathology. I would like to add that DGR is considered by many researchers as a precancerous condition [22-24].

\section{Linkage to Colon Cancer}

One of the theories of carcinogenesis is Virchow's theory, the essence of which lies in the constant pathological irritation of organs and tissues. In the etiopathogenesis of colon cancer, bile acids, especially secondary ones, are considered from this position. Excessive amounts of bile acids, an increase in the time of their contact with the mucous membrane of the colon and is considered by some authors as one of the links in the development of colon cancer. Normally, $80-90 \%$ of bile acids are absorbed in the distal ileum. With the failure of the ileocecal locking apparatus in conditions of reflux enteritis, this function of the ileum worsens and a significant portion of the bile acid pool passes into the large intestine and has a pathological effect on it. So, according to GG 
Nemsadze et al. [25] The concentration of bile acids in NBZ was $12.3 \pm 2.1 \mathrm{mg} / \mathrm{g}$ dry weight of feces, with a normally functioning Bauhinia choke - only $8.5 \pm 1.9 \mathrm{mg} / \mathrm{g} 25$. Mastromarino et al. [26]. found that the activity of bile acid metabolites in feces was much higher in patients with colon cancer than in control persons 26. MQ Hill [22-24] notes that the concentration of bile acids in the feces in various populations correlates with the risk of developing colon cancer. In animal experiments, when colon cancer was caused by dimethylhydrazine, it was shown that an induced change in the concentration of fecal bile acids, which was caused by the diversion of bile to the cecum, was accompanied by an increase in the number of cases of colon cancer 24. From the NBZ position, the microflora in the ileum is the starting point in the development of reflux enteritis, which may further lead to colon carcinogenesis. This is confirmed by the fact that in experiments on the development of experimental colon cancer in sterile animals [27] and animals treated with antibiotics [28], the number of cancer tumors is much less than in animals with normal microflora. KS Ormantaev et al [29]. in 55 sick children with recurrent chronic inflammatory process in the ileocecal zone revealed a higher content of bile acids in feces in patients with NBZ than without it 29. The fact that with right-side hemicolectomy at the site of the confluence of the small intestine into the large intestine valve of absolute action should be formed in order to prevent cancer of the remaining colon, according to GG Nemsadze et al [25]. They noted that after the right-sided hemicolectomy was performed with ileotransversion anastomosis "side-by-side", the average level of bile acids in the dry mass of feces was $14.7 \pm 3.5 \mathrm{mg} / \mathrm{g}$, whereas before the operation it was $10.9 \pm$ 2, $9 \mathrm{mg} / \mathrm{g}$. After the same operation, but with the imposition of a transverse invagination anastomosis according to YaD Vitebsk [19] as more areflux, the average level of bile acids in the feces was 11.9 $\pm 2.6 \mathrm{mg} / \mathrm{g}$ dry weight, whereas before the operation it was $11.7 \pm$ $2.6 \mathrm{mg} / \mathrm{g}$. The last type of anastomosis practically did not change the concentration of bile acids in the faeces.

These examples indirectly indicate the need for the Bauhinia valve to function as an absolute valve. When NBZ, proven irrigoskopii, we conducted a study of biopsy specimens of the mucous membrane of the colon, which allowed to establish different degrees of inflammation with infiltration of lymphoid cells in almost all cases (96\%), histiocytes (46\%) and plasma cells (24\%). Phenomena of edema occurred in $92 \%$ of cases, fibrosis - in 56\%. In addition, hemorrhages, vascular congestion, as well as the proliferation of the intestinal epithelium (27\%), increased mucus formation and mucosal atrophy were detected. With fibrocolonoscopy, $86 \%$ of patients showed signs of colitis, more than half of the patients (53\%) had a total character, and $33 \%$ had a regional one. The Bauhinia valve was closed in $16 \%$ of cases, gaping in $46 \%$. With an irrigoscopy before surgery, colitis was observed in $87 \%$ of patients, with follow-up after surgery only in $16 \%$. When sigmoidoscopy before the operation in $100 \%$ of cases, the phenomena of proctosigmoiditis were detected, after the operation, the effects of unexpressed colitis were noted only in
$25 \%$. With control fibrocolonoscopy, colitis was detected in $47 \%$ of patients, in $26 \%$ of patients with segmental, and in $21 \%$ of cases with diffuse. In the ileum after surgery to hold the device failed. The study of biopsy specimens of the mucous membrane of the colon during the follow-up examination also confirmed the regression of inflammation. Thus, the phenomena of fibrosclerosis were recorded in $39 \%$ of cases, round-cell infiltration - in 35\%, infiltration with plasma cells - in 4\%, infiltration with lymphoid cells - in 39\%, edema - in 8\%, proliferation of intestinal epithelium - in 35\%. Thus, Bauhinoplasty in our modification significantly reduced the degree of inflammation of the colon, which generally reduces the risk of developing the cancer process. Clinical manifestations of NBZ were revealed by us in 106 patients with histologically proven colon cancer (Table 1). The table shows that a significant proportion of patients with an oncologic process in the large intestine has a clinic of the NBZ, which confirms the involvement of the NBZ in colon carcinogenesis. The elimination of the deficiency of the Bauhinia valve and the use of the reflux anastomosis open up the possibilities of surgical prevention of the occurrence of pretumor diseases and colon cancer. Thus, on the basis of the accomplished scientific and practical work, the expediency of which is confirmed by 4 patents (patent No. 1790397 for the invention "Bauginoplasty Method"; patent No. 202664 for the invention "Bauginoplasty Method"; patent No. 2150110 for the invention "Method for the diagnosis of primary insufficiency of the Bauginia valve" ; the decision to grant a patent for an invention "Method of treatment of bronchial asthma on application No. 99103961), defended a thesis for the degree of candidate of medical sciences in 1994, put forward hypotheses about a new approach de treatment of known diseases. From the position of valvular gastroenterology, it is proposed to solve the problems of diseases of the digestive system, including the prevention of oncological processes of this localization. These proposals are justified by obtaining the first positive results in the treatment of some extraintestinal nosological forms that are currently not well understood in the development of medicine. The author proposes to combine the efforts of scientific and practical medicine in the study of the possibilities of valvular gastroenterology.

\section{References}

1. Vitebsky YaD (1999) Basics of valve gastroenterology. Chelyabinsk: South Ural book publishing house, pp. 303.

2. Mechnikov II (1962) Academic Collected Works.

3. Mechnikov II (1908) Studies on the nature of man.

4. Nogaller AM (1989) Chronic colitis and dyskinesia of the colon. Tashkent: Medicine, pp. 211.

5. Klimov AN, Nikulcheva NG (1995) Lipids, lipoproteins and atherosclerosis. St. Petersburg: Peter 297.

6. Troshina VP, Alyasova AV (1993) Features of lipid metabolism in patients with chronic colitis with concomitant insufficiency of the ileocecal locking system and solarheagia. Nizhny Novgorod Medical Journal 3: 80-81.

7. Nogaller AM (1975) Allergy and chronic diseases of the digestive system (diagnosis and treatment of food, microbial and tissue allergies) M: Medicine, pp. 227. 
8. Martynov VL, Myasnikov IG, Panteleeva RA (1995) Syndrome of vegetative dystonia and dysfunction of the gastrointestinal tract. In the book: VII Vseros. Congress of Neurologists.

9. Chuchalin AG (1997) Bronchial asthma. T 1-2 M: Medicine.

10. Torgushina NS, Martynov VL (1995) Changes in the skin of patients with insufficiency of the bauhinia valve. In: Proceedings of the conference Actual problems of coloproctology.

11. Marks I, Shuster S (1970) Dermatogenic enteropathi. Gut 11: 292-298.

12. Polak IM, Bloom IR, Wright NA, Butler U (1989) Physiology of the gut.

13. Ebert R (1980) Greutzfeladt W Clinics in Gastroenterology 9: 679-698.

14. Ross SA, Shaffer EA (1981) Gastroenterology 86: 108-111.

15. Davenport G (1965) Gastroenterology 49: 189.

16. Lawson HH (1964) Effect of Duodenal Contents on the Gastric Mucosa Under Experimental Conditions Lancet 1: 469-472.

17. Kirk RM (1970) Experimental gastric ulcers in the rat: The separate and combined effects of vagotomy and bile-duct implantation into the stomach. Brit Journ Surg 57(7): 521-524.

18. Lawson HH (1972) The reversibility of postgastrectomy alkaline reflux gastritis by a Roux-en-Y loop. Brit Journ Surg 59(1): 13-15.

19. Vitebsk Ya D (1976) Chronic disorders of duodenal permeability and gastric ulcer and duodenal ulcer. Chelyabinsk: South Ural book publishing house, pp. 188

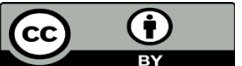

This work is licensed under Creative Commons Attribution 4.0 License

To Submit Your Article Click Here:

Submit Article

DOI: $10.32474 /$ CTGH.2019.02.000133

20. Dragstedt LR (1956) Gastroenterology 30: 20.

21. Kazimirov LI (1971) To the question of surgical treatment of duodenostasis. In the book: Issues of thoracic and abdominal surgery. Bitter: Publishing House GMI, pp. 317-326.

22. Hill MQ (1977) Bacterial factors. Topics in Gastroenterology 5: 45-64.

23. Hill MQ (1981) Metabolic epidemiology of large bowel cancer. Gastrointestinal cancer Q De Cosse, P Sherlock.

24. Hill MQ (1988) Gastroenterology. M: Medicine, PP. 235-252.

25. Nemsadze GG (1990) The functional state of the ileocecal locking apparatus in patients with colon cancer. Bulletin of Surgery 4: 21-23.

26. Mastromarino A, Reddy BS Wynder EL (1976) An enzymatic activity of the local flora. American Journal of Clinical Nutrition 29: 1455-1460.

27. Reddy BS, Narisawa J, Maronpot R, Weisburger Q Wynder EL (1975) Animal bowling. Cancer Research 35: 3421-3426.

28. Loedin BR, Lorbach SL (1981) Effect of antibiotics induced by 1,2-dimethylthydrozine dichloride. Journal of the National Cancer Institute 67: 877-880.

29. Ormantaev KS, Akhparov NN, Osipov RR (1999) Clinical and functional diagnosis and surgical treatment of ileocecal locking insufficiency in children. Pediatric Surgery 1: 6-9.

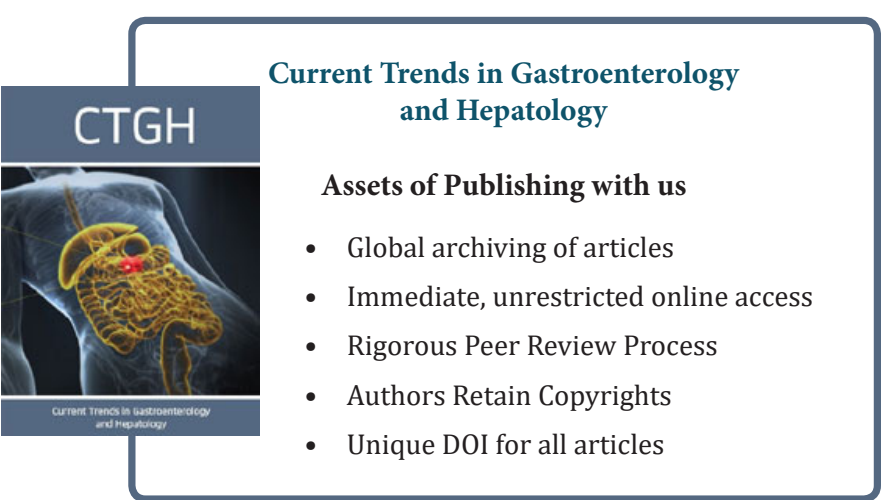

